\title{
Toward sustainable syntheses of Ca-based MOFs
}

\author{
Tom. S. Crickmore, ${ }^{a}$ Haamidah Begum Sana, ${ }^{a}$ Hannah Mitchell, ${ }^{a}$ Molly Clark ${ }^{a}$ and Darren \\ Bradshaw*a
}

Received 00th January 20xx, Accepted 00th January 20xx DOI: $10.1039 / x 0 x \times 00000 x$

\begin{abstract}
We report the use of benign and green precursors, including waste chicken eggshells and PET (polyethylene terephthalate) from recycled plastic bottles, for the facile synthesis of a variety of calcium-based metal-organic frameworks (Ca-MOFs), using water based and mechanochemical synthesis techniques.
\end{abstract}

Metal-organic frameworks are a class of porous and polymeric material composed of metal nodes and organic linkers. ${ }^{1}$ Diverse applications of this material class include light molecule adsorptions ${ }^{2}$, catalysis, ${ }^{3}$ separation ${ }^{4}$ and drug delivery. ${ }^{5}$ As the research field reaches a level of maturity where industrialisation comes into focus, one must start to consider the broader aspects of material production, including the associated costs as well as the environmental impacts of precursors and synthetic procedures. ${ }^{6}$ In order to fully exploit this class of materials the area must look towards sustainable and facile syntheses that do not require the use of large quantities of often toxic solvents and shift toward green precursor sources.

Solid metal sources ${ }^{7}$ such as hydroxides, ${ }^{8}$ oxides $^{9}$ and carbonates ${ }^{10,11}$ have been extensively used in MOF synthesis, both as direct metal ion sources and sacrificial templates. Metal carbonates such as those of calcium and copper are highly abundant naturally occurring minerals, that upon reaction with carboxylate-based linkers such as terephthalic acid $\left(\mathrm{H}_{2} \mathrm{BDC}\right)$ and squaric acid $\left(\mathrm{H}_{2} \mathrm{SQ}\right)$ form MOFs in excellent yield, while producing only mild by-products (water and carbon dioxide). Sumida et al. demonstrated that biomineralized calcium carbonate, in the form of coral, sea urchin skeletons and eggshells can be used as metal sources for the formation of calcium-based MOF (Ca-MOFs) facsimiles of these natural structures. ${ }^{10}$ While Riccò et al. recently showed that the naturally occuring minerals malachite and azurite, polymorphs

a. School of Chemistry, University of Southampton, Highfield Campus, Southampton SO171BJ, U.K.D.Bradshaw@soton.ac.uk.Twitter: @MOFSoton

+ Footnotes relating to the title and/or authors should appear here.

Electronic Supplementary Information (ESI) available: [details of any supplementary information available should be included here]. See DOI: 10.1039/x0xx00000x of copper carbonate, can be used in the synthesis of the widely studied framework HKUST-1 upon reaction with trimesic acid. ${ }^{11}$

Recycling of plastics has also been employed as a strategy toward renewable linker sources in MOF synthesis, including PET (polyethylene terephthalate) and PLA (poly-lactic acid) ${ }^{12}$ from bottles and cups, respectively. PET is one of the most utilised plastics for a wide range of products, most notably single-use packaging. Recycling of PET has drastically improved in recent years, however new technologies to utilise this environmentally persistent material are still necessary. ${ }^{13}$ PET contains up to $85 \mathrm{wt} \%$ terephthalate monomers and thus can be used as a source of terephthalic acid for MOF formation upon depolymerisation. ${ }^{14}$ Deleu et $a .^{15}$ and Ren et al. ${ }^{16}$ first demonstrated the use of PET in the synthesis of various MIL (MIL = Materials Institute Lavoisier) family MOFs via one-pot solvothermal syntheses, exploiting the matching temperature requirements for simultaneous PET hydrolysis and MIL assembly. Since then, hydrolysis of PET to yield terephthalic acid in MOF syntheses has been applied to both nickel ${ }^{17}$ and tin frameworks, ${ }^{18}$ and a thermally robust water-stable hcp form of UiO-66. ${ }^{19}$

Mechanochemical techniques such as ball-milling, ${ }^{20}$ screw extrusion ${ }^{21}$ and, very recently, liquid-assisted resonant acoustic mixing 22 have been shown as rapid and largely scalable processes for the synthesis of a wide-range of MOF materials. The use of little or no solvent, fast reaction times and when used in combination with solid metal carbonate precursors, ${ }^{23,24}$ means that mechanochemical techniques offer a green alternative to traditional solvothermal MOF syntheses especially if one or more renewable framework precursor sources can be accessed.

The benign toxicity and low density of calcium-based MOFs are becoming increasingly desirable for applications in adsorption, separation and drug delivery, ${ }^{25}$ and in this work we develop facile sustainable synthetic routes (scheme 1) to three representative Ca-MOFs: $\mathrm{Ca}(\mathrm{SQ})\left(\mathrm{H}_{2} \mathrm{O}\right)$ ( $\mathrm{SQ}=$ squarate), $\mathrm{Ca}(\mathrm{FU})\left(\mathrm{H}_{2} \mathrm{O}\right)_{3}(\mathrm{FU}=$ fumarate $)$ and $\mathrm{Ca}(\mathrm{BDC})\left(\mathrm{H}_{2} \mathrm{O}\right)_{3} \quad(\mathrm{BDC}=$ 

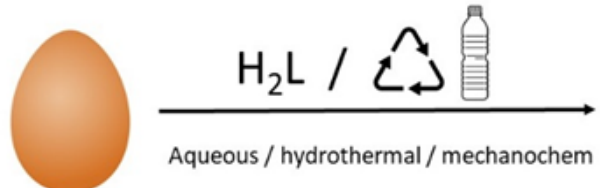

Aqueous / hydrothermal/mechanochem

Scheme 1. Illustrative reaction scheme for the preparation of Ca-based MOFs from green precursors and sustainable synthesis techniques.

benzene-1,4-dicarboxylate (terephthalate)) (fig. S1). We demonstrate the bulk synthesis of these materials using waste chicken eggshells as a renewable calcium carbonate source in water or in combination with largely solvent-free mechanochemical techniques. Significantly, $\mathrm{Ca}(\mathrm{BDC})\left(\mathrm{H}_{2} \mathrm{O}\right)_{3}$ can be synthesised solvothermally in a one-pot synthesis, utilising eggshells and recycled PET plastic bottles as sustainable precursors, and also mechanochemically using reclaimed BDC following the pre-hydrolysis of the polymer. By showcasing these environmentally friendly syntheses we demonstrate viability towards the upscale, development and commercialisation of this important class of materials.

$\mathrm{Ca}(\mathrm{SQ})\left(\mathrm{H}_{2} \mathrm{O}\right)$ was initially prepared from commercial $\mathrm{CaCO}_{3}$ (calcite polymorph) by simply adding the metal carbonate to an aqueous solution of squaric acid and stirring for 24 hours at room temperature. An immediate colour change of the solution from colourless to purple and effervescence from carbon dioxide production signified reaction had occurred. A previous synthesis of this $\mathrm{MOF}$ from $\mathrm{CaCO}_{3}$ has been reported but utilised microwave heating (albeit for a short time). ${ }^{10}$ Full characterisation, including powder X-Ray diffraction (PXRD) (fig. 1A), thermogravimetric analysis (TGA) (fig. S7) and scanning electron microscopy (SEM) (fig. 1C) confirmed the formation of the Ca-squarate MOF and that no residual calcium carbonate precursor remained. This is significant given the lack of heating and relative insolubility of calcite.

The topologically identical frameworks $\mathrm{Ca}(\mathrm{FU})\left(\mathrm{H}_{2} \mathrm{O}\right)_{3}$ and $\mathrm{Ca}(\mathrm{BDC})(\mathrm{H} 2 \mathrm{O})_{3}$ could also be prepared directly from calcite, but hydrothermal syntheses were necessary in order for the ligand to adequately dissolve for framework assembly. In the case of $\mathrm{Ca}(\mathrm{FU})\left(\mathrm{H}_{2} \mathrm{O}\right)_{3}$, after heating at $100^{\circ} \mathrm{C}$ for $24 \mathrm{hrs}$ a clear solution resulted from which large colourless crystals of the MOF formed after 1 day (fig. S15). Both frameworks were characterised fully by PXRD (fig. 2A \& 2C), SEM (fig. 2B \& 2D) and TGA (fig. S16 \& S18).

To investigate the wider sustainability of Ca-MOF syntheses, we directly replaced the commercial $\mathrm{CaCO}_{3}$ with waste chicken eggshells as the $\mathrm{Ca}$ (II) source, focussing on the bulk synthesis of the materials rather than framework replication of the hierarchical biomineral structure. The chicken eggshells were firstly characterised to confirm their composition through PXRD (fig. S3), TGA (fig. S4), SEM (fig. S5) and Fourier transform infrared spectroscopy (FTIR) (fig. S6). The interior organic membrane of the shell was removed mechanically prior to characterisation. The shells were then dried at $70{ }^{\circ} \mathrm{C}$ for one hour followed by complete grinding in a pestle and mortar. PXRD and FTIR confirmed that the eggshell consisted wholly of calcite. TGA characterisation of both membrane intact and membrane removed samples confirmed that our method could remove most organics present on the interior surface, resulting in a residual mass $(\mathrm{CaO})$ of $53 \%$ compared to an expected value of $56 \%$ for pure calcite. As expected, SEM confirmed that the ground eggshells have irregular particle size and morphology.

In all cases the ground eggshells could be directly used in place of commercial $\mathrm{CaCO}_{3}$ under the previously determined reaction conditions with no evidence of residual calcite present in any of the three MOF products (fig. S8, 1A, 2A \& C). The addition of a larger eggshell fragment (membrane removed) to an equimolar solution of $\mathrm{H}_{2} \mathrm{SQ}$ expectedly caused effervescence and the formation of MOF crystals on the surface of the shell after a few days when left at room temperature under static conditions. This initial crystal growth was visualised via SEM (fig. 1D) and is reminiscent of the coordination replication work developed by Sumida et al. ${ }^{10}$ After standing for a further week the eggshell fully transformed to the squarate MOF (fig. 1A). Remarkably, the slow crystallisation of the squarate MOF yielded $X$-ray quality single crystals nucleating on and growing outwards from the interior and exterior surfaces of the eggshell (fig. 1B \& S9). We found that keeping the organic membrane intact to the eggshell however partially inhibits the formation of large crystals on the shell interior (fig. S10 \& S11), and thus crystallisation to some extent can be influenced by the presence of this semi-impermeable organic layer as occurs in matrixmediated biomineralisation processes.

Only $\mathrm{Ca}(\mathrm{SQ})\left(\mathrm{H}_{2} \mathrm{O}\right)$ was found to be accessible from calcite (commercial or eggshells) under room temperature aqueous conditions, so the preparation of all three frameworks were also investigated using liquid assisted grinding (LAG) techniques. This method has previously been reported for a range of alkaline earth tetrafluoro-terephthalate frameworks by ballmilling the linker with the corresponding metal hydroxide. ${ }^{26,27}$

Commercial $\mathrm{CaCO}_{3}$ and excess $\mathrm{H}_{2} \mathrm{SQ}$ were combined in a Teflon-lined vessel along with several $\mathrm{ZrO}_{2}$ balls. The reaction was shaken for five minutes at $50 \mathrm{~Hz}$, to ensure a homogeneous

Fig. 1 A) PXRD comparison of synthesised $\mathrm{Ca}(\mathrm{SO})\left(\mathrm{H}_{2} \mathrm{O}\right)$ from various precursors to a simulated pattern; $B$ ) Image of $\mathrm{Ca}(\mathrm{SQ})\left(\mathrm{H}_{2} \mathrm{O}\right)$ crystals on the surface of an eggshell; C) SEM image of $\mathrm{Ca}(\mathrm{SQ})\left(\mathrm{H}_{2} \mathrm{O}\right)$ synthesised from $\mathrm{CaCO}_{3}$ (scale bar $=10 \mu \mathrm{m}$ ); D) SEM image of $\mathrm{Ca}(\mathrm{SQ})\left(\mathrm{H}_{2} \mathrm{O}\right)$ crystals on the surface of an eggshell (scale bar $=100 \mu \mathrm{m}$ ).
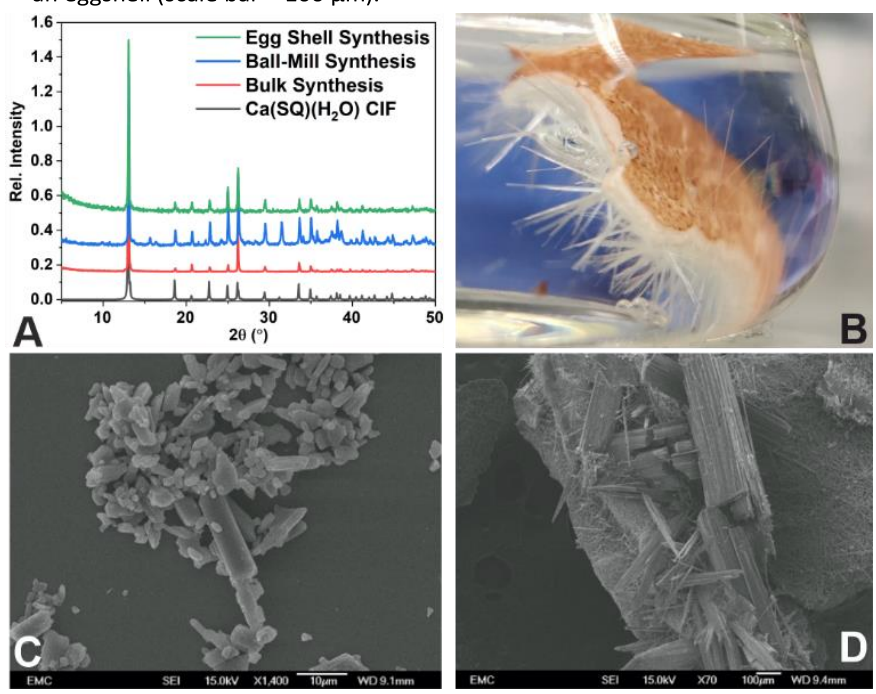
mixture prior to $50 \mu \mathrm{L}$ of deionised water being added to the vessel, and shaken at the same frequency for a further 20 minutes. PXRD of the resulting purple powder confirmed no remaining $\mathrm{CaCO}_{3}$ was present in the product. After this, the powder was washed with water and recovered by centrifugation for three cycles. Our facile room temperature synthesis of $\mathrm{Ca}(\mathrm{SQ})\left(\mathrm{H}_{2} \mathrm{O}\right)$ in water demonstrates that if any calcite remained in the ball-milled product post-synthesis then the water washing step could promote its transformation with any unreacted $\mathrm{H}_{2} \mathrm{SQ}$ leading to MOF formation. It is therefore important to characterise prior to washing to confirm that it is in fact the ball-milling that forms $\mathrm{Ca}(\mathrm{SQ})\left(\mathrm{H}_{2} \mathrm{O}\right)$ rather than a post-milling reaction which is indeed the case. SEM imaging (fig. S12) demonstrates that the MOF crystals synthesised mechanochemically are much smaller and symmetrical than those synthesised in water, with longest dimensions of up to $1 \mu \mathrm{m}$ and $10 \mu \mathrm{m}$ by these two methods, respectively.

It was found difficult to mechanochemically transform eggshells completely to the squarate MOF, with unreacted calcite and linker still present in the product (fig. S13). Washing this material with deionised water appeared to promote the reaction of the remaining eggshells with the organic linker consistent with this reaction occurring in water. While the changes in the diffraction patterns support this assertion, it is also likely that some of the squaric acid is simultaneously washed from the sample.

$\mathrm{N}_{2}$ gas adsorption experiments of $\mathrm{Ca}(\mathrm{SQ})\left(\mathrm{H}_{2} \mathrm{O}\right)$ synthesised from egg shells under aqueous conditions and via ball-milling yielded BET surface areas of 348 and $292 \mathrm{~m}^{2} / \mathrm{g}$ respectively (fig. S14), which is comparable to a reported $\mathrm{CO}_{2}$ BET value of 224 $\mathrm{m}^{2} / \mathrm{g} \cdot{ }^{28}$

Calcium carbonate and fumaric acid were reacted under the same milling condition with deionised water $(20 \mu \mathrm{L})$. PXRD (fig. 2A) and TGA (fig. S16) confirmed the formation of the desired

Fig. 2. A) PXRD of $\mathrm{Ca}(\mathrm{FU})\left(\mathrm{H}_{2} \mathrm{O}\right)_{3}$ synthesised via hydrothermal and ballmilling techniques; B) SEM image of $\mathrm{Ca}(\mathrm{FU})\left(\mathrm{H}_{2} \mathrm{O}\right)_{3}$ synthesised via ball-milling. Scale bar $=1 \mu \mathrm{m} ; \mathrm{C})$ PXRD of $\mathrm{Ca}(\mathrm{BDC})\left(\mathrm{H}_{2} \mathrm{O}\right)_{3}$ synthesised via a reported bulk synthesis as well as solvothermal and ball-milling techniques; D) SEM image of $\mathrm{Ca}(\mathrm{BDC})\left(\mathrm{H}_{2} \mathrm{O}\right)_{3}$ synthesised solvothermally from eggshells and PET. Scale bar $=1 \mu \mathrm{m}$.
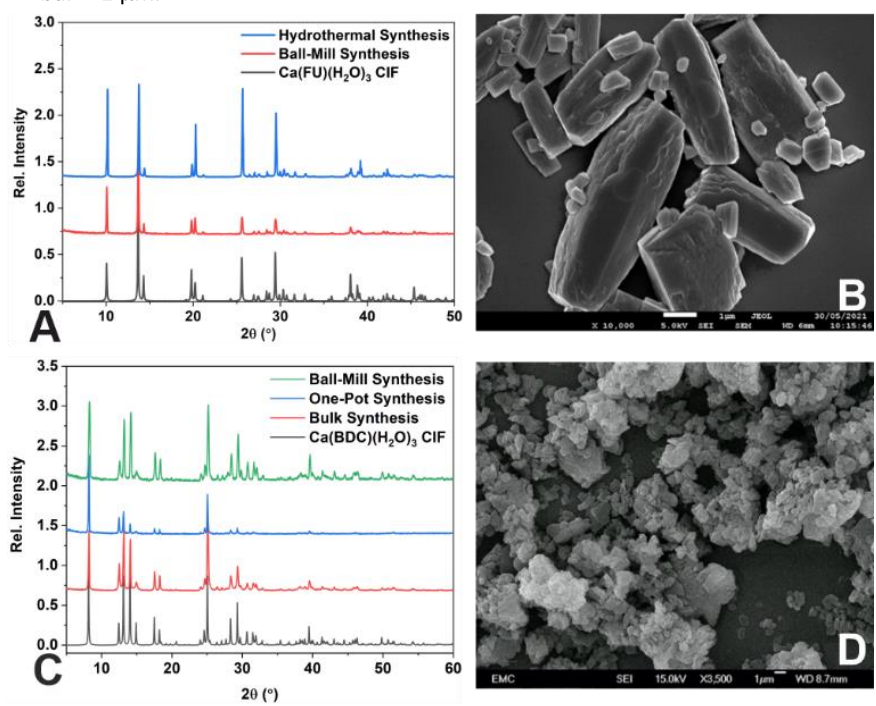

$\mathrm{Ca}(\mathrm{FU})\left(\mathrm{H}_{2} \mathrm{O}\right)_{3}$ phase. Again, replacing the calcium carbonate with the same molar quantity of ball-milled eggshells the fumarate MOF could also be formed under these conditions. This is a step forward in the synthesis of $\mathrm{Ca}(\mathrm{FU})\left(\mathrm{H}_{2} \mathrm{O}\right)_{3}$ which typically involves large solvent quantities, prolonged heating or long crystallisation times. ${ }^{29}$ We note that replacing fumaric acid with its disodium salt in the mechanochemical synthesis failed to form the MOF (fig. S17), confirming the importance of reacting stable, carbonate-based metal precursors with acidic organic linkers under ball-milling conditions.

Finally, for $\mathrm{Ca}(\mathrm{BDC})\left(\mathrm{H}_{2} \mathrm{O}\right)_{3}$ we have investigated its synthesis by employing a combination of sustainable and green precursors, namely eggshells as the $\mathrm{Ca}$ (II) source and PET for the linker.

Ground eggshells and PET flakes from recycled PET plastic bottles were initially combined in a Teflon-lined autoclave with a water/ethylene glycol solvent mixture (10:1) and heated to $210{ }^{\circ} \mathrm{C}$ for 15 hours, yielding $\mathrm{Ca}(\mathrm{BDC})\left(\mathrm{H}_{2} \mathrm{O}\right)_{3}$. PXRD and TGA confirmed the presence of the framework and some unreacted calcite in the product. Ball-milling the eggshells for a short amount of time prior to MOF synthesis did however resolve this issue by increasing the surface area of the sustainable metal precursor. We believe that the non-porous nature of $\mathrm{Ca}(\mathrm{BDC})\left(\mathrm{H}_{2} \mathrm{O}\right)_{3}$ means that MOF formation on the surface of calcite crystals likely inhibits further MOF growth, as there is limited opportunity for both further leaching of $\mathrm{Ca}(\mathrm{II})$ or impregnation of $\mathrm{BDC}^{2-}$ through the initially deposited dense MOF layer. Increasing the surface area of the eggshells via mechanical means is thus an essential step in cleanly forming high yields of the MOF without unreacted calcite. PXRD (fig. 2C), TGA (fig. S18) and SEM (fig. 2D) confirmed that the product formed from ball-milled eggshells and PET under solvothermal conditions was phase pure $\mathrm{Ca}(\mathrm{BDC})\left(\mathrm{H}_{2} \mathrm{O}\right)_{3}$.

Our attempts to synthesise the MOF mechanochemically directly from eggshells and intact PET proved unsuccessful, most likely due to the slow rate of PET breakdown and difficulty in reaching the high energy input necessary for effective depolymerisation to BDC. Recent reports do however demonstrate that aging the $\mathrm{PET},{ }^{30}$ in one case in the presence of an enzyme, ${ }^{31}$ does allow for mechanochemical depolymerisation. Thus a one-pot mechanochemical synthesis of $\mathrm{Ca}(\mathrm{BDC})\left(\mathrm{H}_{2} \mathrm{O}\right)_{3}$ from waste materials has viability under the correct conditions. We have however been successful in synthesising $\mathrm{Ca}(\mathrm{BDC})\left(\mathrm{H}_{2} \mathrm{O}\right)_{3}$ via ball-milling using eggshells as the calcium source, and terephthalic acid that had been previously reclaimed from the hydrolysis of PET plastic bottles. PET bottles were pre-hydrolysed to $\mathrm{H}_{2} \mathrm{BDC}$ (denoted as reclaimed $\mathrm{H}_{2} \mathrm{BDC}$ ) via a method described by Ren et al. ${ }^{16}$ Full characterisation including ${ }^{1} \mathrm{H}$ nuclear magnetic resonance (NMR) (fig. S21), FTIR (fig. S22), reverse phase ultra-high performance liquid chromatography mass spectrometry (RP UHPLC MS) (fig. S23) and PXRD (fig. S24) confirmed the formation of $\mathrm{H}_{2} \mathrm{BDC}$ in good yield. This method also resulted in the formation of $X$-ray quality crystals whose unit cell parameters matched well to literature values (CCDC 2042484) (table S2). Reclaimed $\mathrm{H}_{2} \mathrm{BDC}$ and calcium carbonate or eggshells were combined with deionised water $(40 \mu \mathrm{L})$ and shaken for 20 
minutes, cleanly producing $\mathrm{Ca}(\mathrm{BDC})\left(\mathrm{H}_{2} \mathrm{O}\right)_{3}$ mechanochemically as confirmed via PXRD (fig. 2C), TGA (fig. S18) and SEM (fig. S19).

On occasion, we found that the mechanochemically produced $\mathrm{Ca}(\mathrm{BDC})\left(\mathrm{H}_{2} \mathrm{O}\right)_{3}$ undergoes a degree of reversible dehydration to a porous phase as previously described by Mazaj et al.,32 resulting in a mixture of MOFs. This typically occurs during the drying step after washing the product to remove any unreacted linker. Further heating of $\mathrm{Ca}(\mathrm{BDC})\left(\mathrm{H}_{2} \mathrm{O}\right)_{3}$ can result in full transformation to the dehydrated phase or, by simply immersing the MOF powder in deionised water the hydrated phase can be recovered (fig. S20).

To conclude, we have demonstrated the use of sustainable precursors based on waste materials and recyclable plastic for the synthesis of Ca-based MOFs under a range of experimental conditions. Importantly, these precursors have been combined with a solvent-minimised mechanochemical synthesis ultimately leading to a highly sustainable preparation of $\mathrm{Ca}(\mathrm{BDC})\left(\mathrm{H}_{2} \mathrm{O}\right)_{3}$ through the ball-milling of eggshells and linkers reclaimed from PET bottles. As MOF research reaches a level of maturity where the focus is shifting towards upscale and industrial adoption, the combined use of sustainable synthesis methods and green resources is likely to become much more commonplace.

\section{Notes and references}

TSC acknowledges the EPSRC and University of Southampton for DTP funding (EP/R513325/1). The authors thank Dr Marina Carravetta and Joshua Le Brocq for access to ball-milling equipment, $\mathrm{Dr}$ Dan Stewart for assistance with nitrogen adsorption and Aran Amin for collection of some SEM images. Most importantly, we thank all lab members for their consumption of eggs and soda to provide the MOF precursors for this work.

1 H. Furukawa, K. E. Cordova, M. O'Keeffe and O. M. Yaghi, Science (80-. )., 2013, 341, 974.

2 H. Li, K. Wang, Y. Sun, C. T. Lollar, J. Li and H. C. Zhou, Mater. Today, 2018, 21, 108.

3 P. García-García, M. Müller and A. Corma, Chem. Sci., 2014, 5, 2979

4 C. Xiao, A. Khayambashi and S. Wang, Chem. Mater., 2019, 31, 3863.

5 P. Markopoulou, N. Panagiotou, A. Li, R. Bueno-Perez, D. Madden, S. Buchanan, D. Fairen-Jimenez, P. G. Shiels and R. S. Forgan, Cell Reports Phys. Sci., 2020, 1, 100254.

6 M. I. Severino Neves, E. Gkaniatsou, F. Nouar, M. L. Pinto and C. Serre, Faraday Discuss., 2021, DOI:10.1039/d1fd00018g.

7 G. Zhan and H. C. Zeng, Chem. Commun., 2017, 53, 72.

8 a) Y. Liu, J. H. Pan, N. Wang, F. Steinbach, X. Liu and J. Caro, Angew. Chemie, 2015, 127, 3071; b) B. Wang, J. Jin, B. Ding, X. Han, A. Han and J. Liu, Front. Mater., 2020, 7, 37; c) H.-F. Wang, L. Chen, M. Wang, Z. Liu and Q. Xu, Nano Lett., 2021, 21, 3640.

9 a) S. El-Hankari, J. Aguilera-Sigalat and D. Bradshaw, J. Mater. Chem. A, 2016, 4, 13509; b) W. W. Zhan, Q. Kuang, J. Z. Zhou, X. J. Kong, Z. X. Xie and L. S. Zheng, J. Am. Chem. Soc., 2013, 135, 1926; c) S. M. Meckler, C. Li, W. L. Queen, T.
E. Williams, J. R. Long, R. Buonsanti, D. J. Milliron and B. A. Helms, Chem. Mater., 2015, 27, 7673

10 K. Sumida, M. Hu, S. Furukawa and S. Kitagawa, Inorg. Chem., 2016, 55, 3700.

11 R. Riccò, O. Linder-Patton, K. Sumida, M. J. Styles, K. Liang, H. Amenitsch, C. J. Doonan and P. Falcaro, Chem. Mater., $2018,30,5630$.

12 B. Slater, S. O. Wong, A. Duckworth, A. J. P. White, M. R. Hill and B. P. Ladewig, Chem. Commun., 2019, 55, 7319.

13 B. Shojaei, M. Abtahi and M. Najafi, Polym. Adv. Technol., 2020, 31, 2912.

14 E.-S. M. El-Sayed and D. Yuan, Green Chem., 2020, 22, 4082.

15 W. P. R. Deleu, I. Stassen, D. Jonckheere, R. Ameloot and D. E. De Vos, J. Mater. Chem. A, 2016, 4, 9519.

16 J. Ren, X. Dyosiba, N. M. Musyoka, H. W. Langmi, B. C. North, M. Mathe and M. S. Onyango, Int. J. Hydrogen Energy, 2016, 41, 18141.

17 K. Song, X. Qiu, B. Han, S. Liang and Z. Lin, Environ. Sci. Nano, 2021, 8, 390.

18 A. Ghosh and G. Das, J. Environ. Chem. Eng., 2021, 9, 105288.

19 L. Zhou, S. Wang, Y. Chen and C. Serre, Microporous Mesoporous Mater., 2019, 290, 109674.

20 T. Stolar, A. Prašnikar, V. Martinez, B. Karadeniz, A. Bjelić, G. Mali, T. Friščić, B. Likozar and K. Užarević, ACS Appl. Mater. Interfaces, 2021, 13, 3070.

21 D. Crawford, J. Casaban, R. Haydon, N. Giri, T. McNally and S. L. James, Chem. Sci., 2015, 6, 1645.

22 H. M. Titi, J. L. Do, A. J. Howarth, K. Nagapudi and T. Friščić, Chem. Sci., 2020, 11, 7578.

23 W. Yuan, J. O'Connor and S. L. James, CrystEngComm, 2010, 12, 3515.

24 I. Brekalo, W. Yuan, C. Mottillo, Y. Lu, Y. Zhang, J. Casaban, K. T. Holman, S. L. James, F. Duarte, P. A. Williams, K. D. M. Harris and T. Friščić, Chem. Sci., 2020, 11, 2141.

25 S. Xian, Y. Lin, H. Wang and J. Li, Small, 2021, 17, 2005165.

26 A.-A. Al-Terkawi, G. Scholz, F. Emmerling and E. Kemnitz, Cryst. Growth Des., 2016, 16, 1923.

27 G. Scholz, F. Emmerling, M. Dreger and E. Kemnitz, Zeitschrift fur Anorg. und Allg. Chemie, 2013, 639, 689.

28 L. Li, L. Guo, S. Pu, J. Wang, Q. Yang, Z. Zhang, Y. Yang, Q. Ren, S. Alnemrat and Z. Bao, Chem. Eng. J., 2019, 358, 446.

29 a) S. Singh, S. Kaushal, J. Kaur, G. Kaur, S. K. Mittal and P. P. Singh, Chemosphere, 2021, 272, 129648; b) F. Ke, C. Peng, T. Zhang, M. Zhang, C. Zhou, H. Cai, J. Zhu and X. Wan, Sci. Rep., 2018, 8, 939.

30 V. Štrukil, ChemSusChem, 2021, 14, 330

31 S. Kaabel, J. P. D. Therien, C. Deschenes, D. Duncan, T. Friscic and K. Auclair, Proc. Natl. Acad. Sci., 2021, DOI:10.1101/2020.07.06.189720.

32 a) M. Mazaj, G. Mali, M. Rangus, E. Žunkovič, V. Kaučič and N. Zabukovec Logar, J. Phys. Chem. C, 2013, 117, 7552; b) M. Mazaj and N. Zabukovec Logar, Cryst. Growth Des., 2015, 15, 617. 